\title{
Antibacterial Activity of Radial Compounds with Peripheral Quaternary Ammonium Units
}

\author{
Jun Kawakami†, Isao Harada, Akio Nakane*, Haruo Kitahara**, Masahiko Nagaki \\ and Shunji Ito \\ Graduate School of Science and Technology, Hirosaki University \\ 3 Bunkyo-cho, Hirosaki, Aomori 036-8561, Japan \\ * Graduate School of Medicine, Hirosaki University \\ 5 Zaifu-cho, Hirosaki, Aomori 036-8562, Japan \\ **Department of Chemistry, Faculty of Education, Hirosaki University \\ 1 Bunkyo-cho, Hirosaki, Aomori 036-8560, Japan \\ †Fax: 81-172-39-3541, e-mail: jun@cc.hirosaki-u.ac.jp
}

Quaternary ammonium functionalized radial compounds $\mathbf{n}-\mathbf{C}_{\mathbf{1 0}} \mathbf{I}(\mathbf{n}=3,4,8,16), \mathbf{n}-\mathbf{C}_{\mathbf{1 0}} \mathbf{B r}(\mathbf{n}=3,4)$ and their reference non-radial compounds $\mathbf{1}-\mathbf{C}_{\mathbf{1 0}} \mathbf{X}(\mathrm{X}=\mathrm{Br}, \mathrm{I})$ were synthesized and their antibacterial properties for gram-positive bacteria (Methicillin-resistant Staphylococcus aureus; MRSA) and gram-negative bacteria (Escherichia coli and Pseudomonas aeruginosa) were investigated. The antibacterial activity for tested bacteria depended on the number of the terminal quaternary ammonium unit, and the influence of the counter anion for antibacterial activity was not observed. The antibacterial activity of $\mathbf{3}-\mathbf{C}_{\mathbf{1 0}} \mathbf{X}(\mathrm{X}=\mathrm{I}, \mathrm{Br})$ for $M R S A$ was the highest in tested bacteria.

Key words: Antibacterial activity, Quaternary ammonium salts, MRSA

\section{INTRODUCTION}

The radial compounds, such as dendrimers [1], provide a very high number of functional groups in a compact space. It is reasonable to expect that these compounds will play a major role as antimicrobial agents because their performance depends on high local concentration $[2,3]$ as shown in Fig. 1.

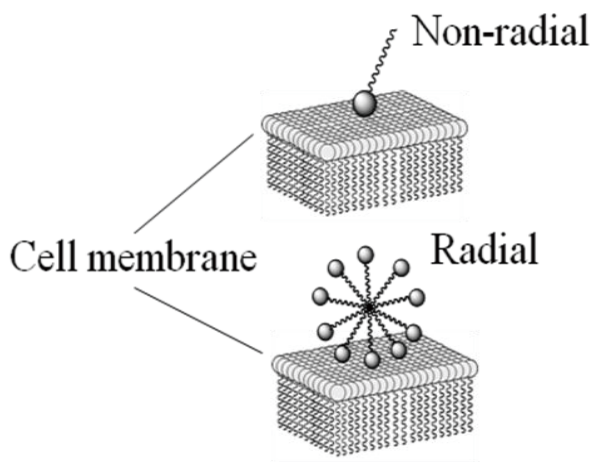

Figure 1. A non-radial antimicrobial agent and a radial antimicrobial agent.

However, there are few studies about the relation between the number of the terminal unit and the antibacterial activity in the radial compounds [2,3]. Therefore, quaternary ammonium functionalized radial compounds $\mathbf{n}-\mathbf{C}_{\mathbf{1 0}} \mathbf{I}(\mathrm{n}=3,4,8,16), \mathbf{n}-\mathbf{C}_{\mathbf{1 0}} \mathbf{B r}(\mathrm{n}=3$, 4) and their reference compounds $\mathbf{1 - C _ { 1 0 }} X(X=B r, I)$ were synthesized and their antibacterial properties for gram-positive bacteria (MRSA) and gram-negative bacteria ( $E$ coli and $P$. aeruginosa) were investigated. Quaternary ammonium compounds have been widely used as disinfectants. They are effective biocidal agents. The structural formulas of $\mathbf{n}-\mathbf{C}_{\mathbf{1 0}} \mathbf{I}(\mathrm{n}=1,3,4$, $8,16)$ and $\mathbf{n}-\mathbf{C}_{\mathbf{1 0}} \mathbf{B r}(\mathrm{n}=1,3,4)$ are shown in Fig. 2.

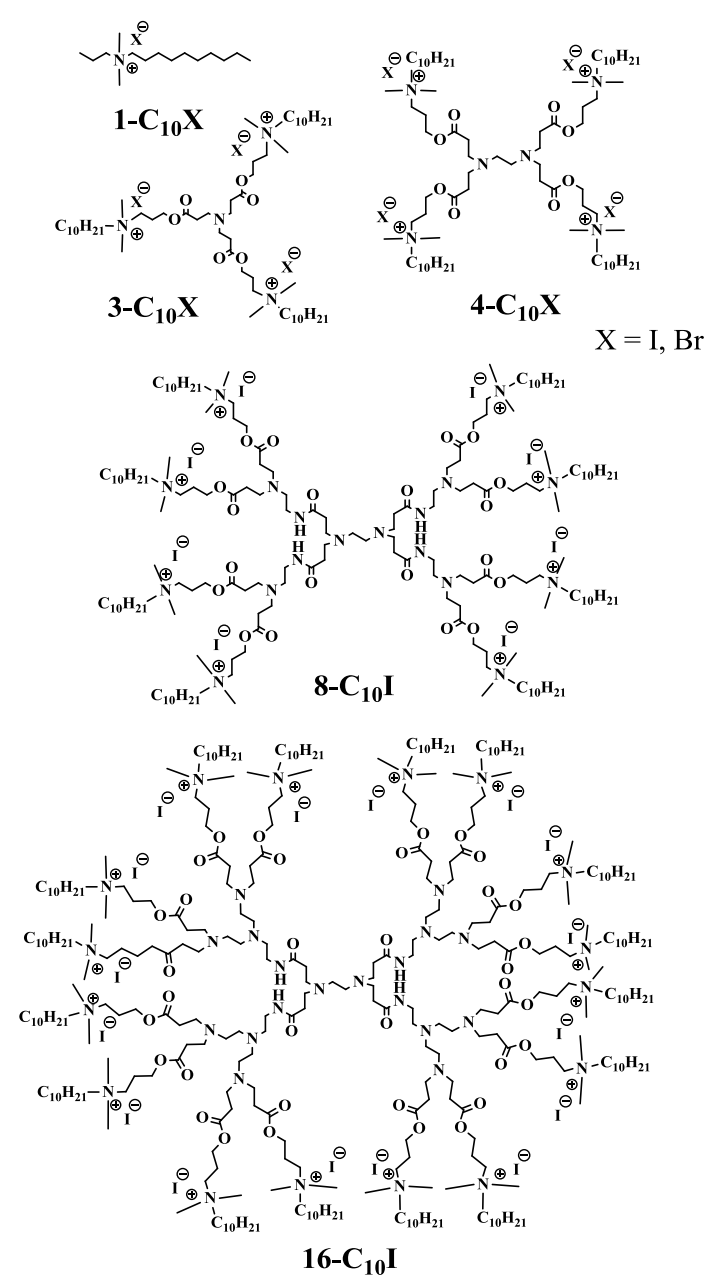

Figure 2. Structural formulas of $\mathbf{n}-\mathbf{C}_{\mathbf{1 0}} \mathbf{I}(\mathrm{n}=1,3,4,8$, 16) and $\mathbf{n}-\mathbf{C}_{\mathbf{1 0}} \mathbf{B r}(\mathrm{n}=1,3,4)$ 


\section{EXPRIMENT}

\subsection{Synthesis}

$\mathbf{n}-\mathbf{C}_{\mathbf{1 0}} \mathbf{I}(\mathrm{n}=1,3,4,8,16)$ and $\mathbf{n}-\mathbf{C}_{\mathbf{1 0}} \mathbf{B r}(\mathrm{n}=1,3,4)$ were obtained by the reaction of 1-harodecane and the corresponding dimethylaminopropyl ester derivatives (Scheme 1).

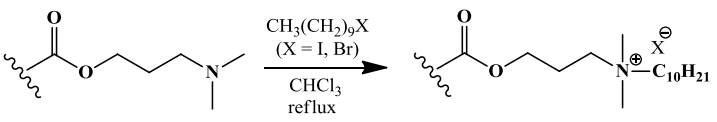

\section{Scheme 1}

The preparation of $\mathbf{3}-\mathbf{C}_{\mathbf{1 0}} \mathbf{I}$ was typical for all $\mathbf{n}-\mathbf{C}_{\mathbf{1 0}} \mathbf{X}$ and involved the corresponding dimethylaminopropyl ester derivatives and 1-iododecane. $0.19 \mathrm{~g}(0.39 \mathrm{mmol})$ of tris(3-dimethylaminopropyl)-3,3',3'-nitrilotripropanoate and $0.41 \mathrm{~g}(1.9 \mathrm{mmol})$ of 1-iododecane were added to a stirred solution of $20-\mathrm{ml}$ chloroform. The stirring was maintained for 2 days under nitrogen atmosphere at $65^{\circ} \mathrm{C}$. After this, the solution was concentrated. The concentrated solution was precipitated in hexane. The mixture was filtered and dried in vacuo, and the product was obtained as a yellow solid material (yield $72 \%$ ). The ${ }^{1} \mathrm{H}$ and ${ }^{13} \mathrm{C}$ NMR spectra of $\mathbf{n}-\mathbf{C}_{\mathbf{1 0}} \mathbf{I}(\mathrm{n}=1,3,4,8$, 16) and $\mathbf{n}-\mathbf{C}_{\mathbf{1 0}} \mathbf{B r}(\mathrm{n}=1,3,4)$ were appropriate. The ${ }^{1} \mathrm{H}$ NMR spectra of $\mathbf{n}-\mathbf{C}_{\mathbf{1 0}} \mathbf{I}(\mathrm{n}=3,4,8,16)$ in $\mathrm{CDCl}_{3}$ are shown in Fig. 3 as typical examples. The ${ }^{1} \mathrm{H}$ NMR spectra of $\mathbf{n}-\mathbf{C}_{\mathbf{1 0}} \mathbf{B r}(\mathbf{n}=1,3,4)$ were the same as those of $\mathbf{n}-\mathbf{C}_{\mathbf{1 0}} \mathbf{I}(\mathrm{n}=1,3,4)$. The electron-spray ionization mass spectra (ESI-MS) of $\mathbf{1}-\mathbf{C}_{\mathbf{1 0}} \mathbf{X}(\mathrm{X}=\mathrm{Br}, \mathrm{I})$ showed corresponding molecular ion peaks $(\mathrm{m} / \mathrm{z} 228.3([\mathrm{M}-\mathrm{X}$ $\left.(\mathrm{X}=\mathrm{Br}, \mathrm{I})]^{+}\right)$.
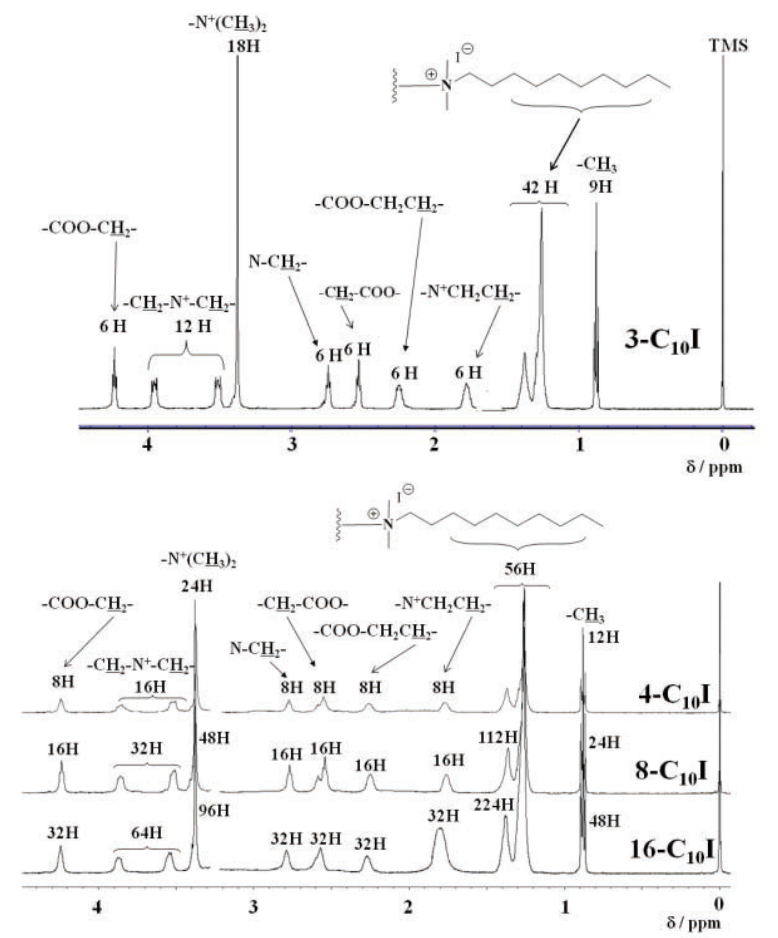

Figure 3. $\quad{ }^{1} \mathrm{H}$ NMR spectra of $\mathbf{n}-\mathbf{C}_{\mathbf{1 0}} \mathbf{I}(\mathrm{n}=3,4,8,16)$ in $\mathrm{CDCl}_{3}$

\subsection{Antibacterial activity test [4, 5]}

Antibacterial activity was investigated in vitro on gram-positive bacteria (MRSA) and gram-negative bacteria ( $E$. coli and $P$. aeruginosa). Overnight bacterial culture was diluted with Mueller-Hinton broth to the density of $1.0 \times 10^{6} \mathrm{CFU}$ (colony forming unit) $/ \mathrm{ml}$. Tested compounds $\left(\mathbf{n}-\mathbf{C}_{\mathbf{1 0}} \mathbf{I} ; \mathrm{n}=1,3,4,8,16 ; \mathrm{X}=\mathrm{I}\right.$ or $\mathrm{Br}$ ) were dissolved in dimethyl sulfoxide and diluted to the concentration 5-1000 $\mu \mathrm{g} / \mathrm{ml}$ with Mueller-Hinton broth. Then, each petri dish was inoculated with the bacterial suspension and incubated at $37^{\circ} \mathrm{C}$ for $24 \mathrm{~h}$. The lowest concentration at which there was no visible growth was taken as the minimal inhibitory concentration (MIC).

\section{RESULTS AND DISCUSSION}

The antibacterial activity of $\mathbf{n}-\mathbf{C}_{\mathbf{1 0}} \mathbf{X}(\mathrm{n}=1,3,4,8,16$; $\mathrm{X}=\mathrm{I}$ or $\mathrm{Br}$ ) was investigated on three different bacteria in culture. Minimal inhibitory concentration (MIC) of $\mathbf{n}-\mathbf{C}_{\mathbf{1 0}} \mathbf{X}(\mathrm{n}=1,3,4,8,16 ; \mathrm{X}=\mathrm{I}$ or Br) against $M R S A, E$. coli, and $P$. aeruginosa were shown in Table. 1 .

Table 1. Antibacterial activity (MIC) of $\mathbf{n}-\mathbf{C}_{\mathbf{1 0}} \mathbf{I}(\mathrm{n}=1$, 3, 4, 8, 16) and $\mathbf{n}-\mathbf{C}_{\mathbf{1 0}} \mathbf{B r}(\mathrm{n}=1,3,4)$ against $M R S A, E$. coli, and $P$. aeruginosa

\begin{tabular}{lccc}
\hline & $M R S A$ & E. coli & P. aeruginosa \\
\hline $\mathbf{1}_{-} \mathbf{C}_{\mathbf{1 0}} \mathbf{I}$ & 60 & 80 & a) \\
$\mathbf{1}_{-} \mathbf{C}_{\mathbf{1 0}} \mathbf{B r}$ & 60 & 80 & a) \\
$\mathbf{3}-\mathbf{C}_{\mathbf{1 0}} \mathbf{I}$ & 4 & 20 & 500 \\
$\mathbf{3}-\mathbf{C}_{\mathbf{1 0}} \mathbf{B r}$ & 4 & 20 & 500 \\
$\mathbf{4}-\mathbf{C}_{\mathbf{1 0}} \mathbf{I}$ & 30 & 70 & a) \\
$\mathbf{4}-\mathbf{C}_{\mathbf{1 0}} \mathbf{B r}$ & 30 & 70 & a) \\
$\mathbf{8}-\mathbf{C}_{\mathbf{1 0}} \mathbf{I}$ & $>80$ & $>80$ & a) \\
$\mathbf{1 6}_{\mathbf{1 6}} \mathbf{C}_{\mathbf{1 0}} \mathbf{I}$ & $>80$ & $>80$ & a) \\
\hline
\end{tabular}

MIC $=$ Minimal inhibitory concentration in $\mu \mathrm{g} / \mathrm{ml}$.

a) inactive

The influence of the counter anion for antibacterial activity was not observed. The most sensitive and least sensitive of the $\mathbf{n}-\mathbf{C}_{\mathbf{1 0}} \mathbf{X}(\mathrm{n}=1,3,4,8,16 ; \mathrm{X}=\mathrm{I}$ or $\mathrm{Br})$ were the $M R S A$ and $P$. aeruginosa, respectively. In fact, in $P$. aeruginosa, all the tested compounds except 3- $\mathbf{C}_{10} \mathbf{X}(\mathrm{X}=\mathrm{I}, \mathrm{Br})$ were inactive. The reason for more potent against gram-positive bacteria $(M R S A)$ and less active against gram-negative bacteria (E. coli and $P$. aeruginosa) was structural difference between gram-positive bacteria and gram-negative bacteria. Gram-positive bacteria tend to have a loose cell wall, while gram-negative bacteria have an outer membrane structure in the cell wall forming an additional barrier for foreign molecules (Fig. 4). It is known that quaternary ammonium compounds are typically more potent against gram-positive bacteria and less active against gram-negative bacteria [3]. In comparison of between radial compounds $\left(\mathbf{n}-\mathbf{C}_{\mathbf{1 0}} \mathbf{X} ; \mathbf{n}=3,4,8,16 ; \mathbf{X}\right.$ 


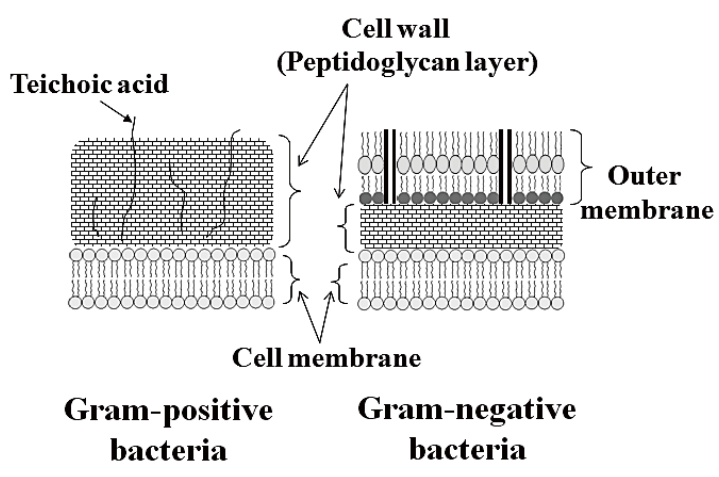

Figure 4. Structural difference between gram-positive bacteria and gram-negative bacteria

$=\mathrm{I}$ or $\mathrm{Br})$ and non-radial compounds $\left(\mathbf{1}-\mathbf{C}_{\mathbf{1 0}} \mathbf{X} ; \mathbf{X}=\right.$ $\mathrm{Br}, \mathrm{I})$ for antibacterial activity, the order of the MIC was

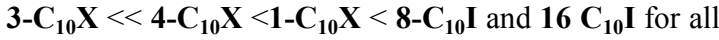
tested bacteria. Antibacterial activity of the radial compounds $\mathbf{n}-\mathbf{C}_{\mathbf{1 0}} \mathbf{X}(\mathrm{n}=3,4 ; \mathrm{X}=\mathrm{I}, \mathrm{Br})$ was higher than that of the non-radial compound $\mathbf{1}-\mathbf{C}_{\mathbf{1 0}} \mathbf{X}(\mathrm{X}=\mathrm{I}, \mathrm{Br})$, but antibacterial activity decreased with increasing of the terminal quaternary ammonium unit number in the radial compounds. The reason for this decreasing antibacterial activity would be cause of steric hindrance. The antibacterial activity of $\mathbf{3}-\mathbf{C}_{\mathbf{1 0}} \mathbf{X}(\mathrm{X}=\mathrm{I}, \mathrm{Br})$ was the highest in all tested bacteria. In particular, the antibacterial activity for MRSA was excellent. The MIC of 3-C $\mathbf{1 0} \mathbf{X}(\mathrm{X}=\mathrm{I}, \mathrm{Br})$ was $4 \mu \mathrm{g} / \mathrm{ml}$.

\section{CONCLUSIONS}

Quaternary ammonium functionalized radial compounds $\mathbf{n}-\mathbf{C}_{\mathbf{1 0}} \mathbf{I}(\mathrm{n}=3,4,8,16), \mathbf{n}-\mathbf{C}_{\mathbf{1 0}} \mathbf{B r}(\mathrm{n}=3,4)$ and their reference non-radial compounds $\mathbf{1 - C _ { 1 0 }} X(X=$
$\mathrm{Br}, \mathrm{I})$ were synthesized and their antibacterial properties for gram-positive bacteria (MRSA) and gram-negative bacteria $(E$. coli and $P$. aeruginosa) were investigated. The influence of the counter anion for antibacterial activity was not observed. Antibacterial activity of the radial compounds $\mathbf{n}-\mathbf{C}_{\mathbf{1 0}} \mathbf{X}(\mathrm{n}=3,4 ; \mathrm{X}=\mathrm{I}, \mathrm{Br})$ was higher than that of the non-radial compound $\mathbf{1}-\mathbf{C}_{\mathbf{1 0}} \mathbf{X}(\mathrm{X}$ $=\mathrm{I}, \mathrm{Br})$, but antibacterial activity decreased with increasing of the terminal quaternary ammonium unit number in the radial compounds. The antibacterial activity of $\mathbf{3}-\mathbf{C}_{\mathbf{1 0}} \mathbf{X}(\mathrm{X}=\mathrm{I}, \mathrm{Br})$ for $M R S A$ was excellent. These compound will applied as antibacterial agent or antibacterial materials.

\section{ACKNOWLEDGMENTS}

The present study was partially supported by a Grant-in-Aid for Scientific Research(C) (No. 17550070) from JSPS and a Grant for Priority Research Designated by the Dean of Graduate School of Science and Technology of Hirosaki University (2005, 2006, 2008, and 2009).

\section{REFERENCES}

[1] D. A. Tomalia, A. M. Naylor, and W. A. Goddard, Angew. Chem. Int. Ed. Engl., 29, 138 -175 (1990).

[2] C. Z. Chen, N. C. Beck, and S. L. Cooper, Chem.. Commun, 1585-1586 (1999).

[3] C. Z. Chen, N. C. Beck-Tan, P. Dhurjat, T. K. van Dyk, R. A. LaRossa, and S. L. Cooper, Biomacromolecules, 1, 473-480 (2000)

[4] Y. Niki et.al., J Infect Chemother, 14, 279-290 (2008).

[5] A. Nagayama, K. Yamaguchi, K. Watanabe, M. Tanaka, I. Kobayashi, and Z. Nagasawa, J Infect Chemother, 14, 383-392 (2008).

(Received May 1, 2010; Accepted November 18, 2010) 